\title{
Concepts of cerebral venous drainage and the aetiology of hydrocephalus
}

\author{
$\mathrm{J}$ Andeweg
}

\begin{abstract}
Evidence is reviewed that an insufficient venous flow from the brain can cause cerebral atrophy and ventricular dilatation. The belief that hydrocephalus could not be caused by venous obstruction is the result of erroneous or inadequate concepts of venous anatomy.
\end{abstract}

The anatomy of collateral venous pathways is important in circumstances of venous insufficiency under experimental or pathological conditions. In his 1956 Caldwell Lecture, the anatomist Batson ${ }^{1}$ concluded that the large vertebral venous plexuses had become forgotten. These plexuses can serve as collateral pathway for outflow of cranial blood when there is obstruction of the jugular veins or superior vena cava. On this basis Bering and Salibi ${ }^{2}$ produced experimental hydrocephalus in dogs by simultaneous occlusion of the jugular veins and part of the vertebral venous system.

The result was still interpreted as an interference with cerebrospinal fluid absorption, but this mechanism cannot explain the occurrence of hydrocephalus when obstruction affects only the deep cerebral venous system. The anatomy of the deep (Galenic) venous system, however, has been controversial for more than a century.

In 1874, Duret ${ }^{3}$ published his extensive investigation of the anatomy of the cerebral arteries, related to necropsy findings and interpretations communicated to him by Charcot. Charcot was very influential, and Duret's work became an important origin of developments in neuropathology; but little attention had been paid to veins. According to Duret, long so-called medullary arteries and veins straight from the convexity would serve the white matter of the centrum semiovale, with short cortical arteries and veins serving only the cortex. The corpus striatum would be supplied by arteries from the base of the brain, but the striate veins would only be directed toward the lateral ventricle. Together with veins from the corpus callosum, Ammon's horn and choroid plexus the striate veins would form the internal cerebral veins terminating in the great vein of Galen. Duret stated that in one case he had succeeded in injecting the ventricular veins through one of the veins of the convexity. He thought it probable that there would be a connection through his "veines médullaires"; any connection between the ventricular veins and the basal vein was apparently unknown to Duret.

In 1888, Hédon ${ }^{4}$ described three anastomotic pathways from the ventricular veins to the basal vein: the striate veins, the vein of the temporal horn (inferior ventricular vein) and the inferior choroidal vein. He also described drainage of the basal vein via the sphenoparietal sinus into the cavernous sinus. $\mathrm{He}$ concluded that the paraventricular white matter drained to the ventricular subependymal veins, not to the convexity via the medullary veins assumed by Duret, whose description of the venous part of the cerebral circulation he found to be erroneous. Hédon did not find venous anastomoses passing through the centrum semiovale.

Hédon's work was forgotten until it was confirmed by Padget ${ }^{5}$ in 1956. Padget added the lateral mesencephalic vein as an anastomosis between the basal vein and lateral sinus, via the superior petrosal sinus.

In 1934, Bedford ${ }^{6}$ reported that ligation of the great vein of Galen in dogs did not cause hydrocephalus, because there was collateral circulation through the striate, thalamic and inferior choroidal veins toward the basal vein. $\mathrm{He}$ did not mention intracerebral anastomoses through the centrum semiovale. Bedford found the basal vein drained mainly to the lateral sinus in dogs, and he believed the basal vein in humans drained only via the great vein of Galen.

In his frequently cited paper, Schlesinger ${ }^{7}$ claimed the existence of anastomoses throughout the centrum semiovale, so that separate obstruction of the deep venous system would be practically impossible. In three monkeys, Schlesinger coagulated the internal cerebral vein on one side. Instead of considering the resulting unilateral hyperaemia to be a manifestation of venous obstruction, he interpreted it as evidence of collateral flow. He called the congested radial venules "intracerebral anastomotic veins", because according to his interpretation they connected ventricular with cortical veins.

Schlesinger also injected the straight sinus in two human brains, at high pressure, and believed that this made the so called intracerebral anastomotic veins visible throughout the hemispheres. An alternative interpretation is that the high pressure caused retrograde 
filling of the thin medullary arteries descending from the cortex into the paraventricular white matter; passage through the capillaries is a pitfall in anatomical injections, causing confusion between arteries and veins.

Schlesinger considered his findings were supported by the work of Pfeifer, ${ }^{8}$ who claimed to have demonstrated veins traversing the centrum semiovale. It was, however, demonstrated by a number of investigators that what Pfeifer described as veins were really arteries and vice versa." Thus the "medullary veins" toward the cortex, described by Pfeifer, must have been arteries.

In her well-known monograph on hydrocephalus, Dorothy Russell ${ }^{10}$ briefly stated that venous congestion as a cause of hydrocephalus became discredited when Bedford and Schlesinger could not confirm that experimental occlusion of the great vein of Galen resulted in hydrocephalus. The above account shows that this view is incorrect. The experiments by Bedford and Schlesinger showed that obstruction of the great vein of Galen alone leaves open many collateral venous pathways.

In 1958, Ferner ${ }^{11}$ described a "venous watershed" in the white matter of the cerebral hemispheres. He investigated the internal cerebral veins and their tributaries by injection of 87 brains from adults. The veins serving the cortex and a layer of subcortical white matter run toward the convexity. Venous flow from the paraventricular white matter is directed toward the ventricle. The great importance of this separate paraventricular venous drainage is that it can explain ventricular dilatation as an atrophy of the paraventricular white matter from insufficient blood flow due to venous obstruction. Thus in cases in which only the deep venous system is involved, the cortex will not be affected. In congenital hydrocephalus the cortex is very often spared.

Kaplan $^{12}$ made injection studies and concluded that anastomoses directly connecting the veins of the cerebral cortex with the Galenic system had not been demonstrated conclusively. Remarkably, he added that these radiating channels should be called "transcerebral veins".

Hassler $^{13}$ injected a contrast agent of low viscosity into the great vein of Galen of 35 human brains. In radiographs of brain slices, very thin (approximately $0.1 \mathrm{~mm}$ ) radiating channels could be seen, totalling several thousands in a hemisphere. Low viscosity, high pressure and long injection time were designed to reach even the smallest veins, but under these conditions retrograde filling of the very thin arteries which descend from the cortex into the white matter will also be obtained, via the capillaries. Hassler regarded the area of capillary filling (in the radiographs whiter than the surroundings) as delineating the region of drainage by the deep cerebral veins. He considered the eventual venous anastomoses too small to be functional, and even maintained that occlusion of the great vein of Galen will generally lead to serious effects. His diagrams of the maximum extent of the deep cerebral venous system are clear illustrations of Ferner's "venous watershed".

\section{Conclusion}

When only the great vein of Galen is occluded, collateral flow will take place toward cavernous and lateral sinus, with the basal vein as an intermediate channel. Anastomotic veins traversing the centrum semiovale are nonexistent or negligible. Instead, a "venous watershed" exists between the paraventricular white matter on one side, and the cortex and subcortical white matter on the other. This makes it possible to explain ventricular dilatation as due to atrophy of the paraventricular white matter, caused by insufficient blood perfusion from hindrance of venous outflow. ${ }^{14}$ Cranial expansion in the infant can still be regarded as a consequence of elevated intracranial pressure.

1 Batson OV. The vertebral vein system. Caldwell Lecture, 1956. Am J Roentgenol 1957;78:195-212.

2 Bering EA, Salibi B. Production of hydrocephalus by increased cephalic-venous pressure. Arch Neurol Psychiatry 1959;81:693-98.

3 Duret $H$. Recherches anatomiques sur la circulation de l'encephale. Arch Physiol Norm Pathol 1874;6:60-91, 316-53, 664-93, 919-57.

4 Hédon E. Étude anatomique sur la circulation veineuse de l'encéphale. Bordeaux: Bellier, 1888.

5 Padget DH. The cranial venous system in man in reference to development, adult configuration, and relation to the arteries. Am J Anat 1956;98:307-55.

6 Bedford THB. The great vein of Galen and the syndrome of increased intracranial pressure. Brain 1934;57:1-24.

7 Schlesinger $B$. The venous drainage of the brain, with special reference to the Galenic system. Brain 1939;62:274-91.

reference to the Galenic system. Brain 1939;62:274-91.
8 Pfeifer RA. Grundlegende Untersuchungen für die Angioarchitektonik des menschlichen Gehirns. Berlin: Springer,
a funter die Angio1930:209-14.

9 Wünscher W, Werner L. Zur Methodik angioarchitektonischer Untersuchungen. Psychiat Neurol Med Psychol 1961;13:1-6.

10 Russell DS. Observations on the pathology of hydrocephalus. London: HMSO, 1949:7.

11 Ferner H. Anatomische und phlebographische Studien der inneren Hirnvenen des Menschen. Z Anat Entwicklungsgesch 1958;120:481-91.

12 Kaplan HA. The transcerebral venous system. Arch Neurol 1959;1:148-52.

13 Hassler O. Deep cerebral venous system in man. Neurology 1966;16:505-11.

14 Andeweg J. Intracranial venous pressures, hydrocephalus and effects of cerebrospinal fluid shunts. Child's Nerv Syst 1989;5:318-23. 